\title{
Música e disco no Brasil: a trajetória do Grupo Eldorado
}

Eduardo Vicente

Mestre em Sociologia pela UNICAMP e doutor em Comunicação pela Escola de Comunicaşões e Artes da Universidade de São Paulo, onde é professor efetivo, atuando na graduação e na pós-graduação.

E-mail: eduvicente@usp.br

Resumo: Esse texto apresenta a trajetória do Grupo Eldorado, de São Paulo, que chegou a ser composto de duas emissoras de rádio (AM e FM), um estúdio, uma gravadora, uma editora musical e uma distribuidora de discos. Sua ênfase, no entanto, será nas atividades do estúdio, criado em 1971, e da gravadora, criada em 1977.

Palavras-chave: Indústria fonográfica, música independente, música popular brasileira, Gravadora Eldorado.
Abstract: This paper presents the trajectory of Eldorado Group from São Paulo, which had even been composed by two radio stations (AM and FM), one sound studio, a recording label, a music publisher and a record distribution company. Nonetheless, this research emphasizes on the activities carried out at the studio, created on 1971, and the recording company, created on 1977.

Keywords: phonographic industry, independent music, Brazilian popular music, Eldorado Records.

A trajetória do Grupo Eldorado representou um marco dentro do cenário musical nacional, seja pela atuação da rádio, criada em 1958, seja pela da gravadora, surgida em 1977. A análise da trajetória do grupo coloca em questão alguns conceitos já estabelecidos nos estudos de comunicação do país, como o da crise do rádio e da estratificação dos meios a partir da chegada da TV e o da produção independente. Além disso, representa um capítulo significativo na história da música erudita e popular do Brasil.

Os depoimentos de João Lara Mesquita e Eduardo Duffles Andrade, que foram utilizados como base para o texto, bem como várias das referências hemerográficas citadas, foram obtidos a partir do projeto O Outro Lado do Disco: A Memória Oral da Indústria Fonográfica, desenvolvido por mim a partir de recursos fornecidos pela Fapesp - Fundação de Amparo à Pesquisa do Estado de São Paulo.

Este trabalho constitui-se como um primeiro passo dentro de um projeto mais amplo, de preservação da história oral da indústria cultural no país. Para tanto, temos procedido ao registro em áudio e vídeo dos depoimentos de profissionais da área de produção fonográfica, ilustrando e complementando a pesquisa 
1. GUERRINI JR., Irineu. Rádio de elite: o papel da Rádio Gazeta no cenário sociocultural de São Paulo nos anos quarenta e cinquenta. Projeto de Pesquisa Docente não publicado. São Paulo, Faculdade de Comunicação Cásper Líbero/ Centro Interdisciplinar de Pesquisa, 2005. que desenvolvi durante o meu doutorado (1998-2002). Os principais objetivos desse levantamento têm sido a discussão do papel de executivos e produtores musicais que, em diferentes momentos, parecem ter exercido uma significativa influência sobre os rumos da indústria e, simultaneamente, a recuperação da memória das gravadoras nacionais tradicionais, que praticamente desapareceram do cenário a partir da década de 1990. Entendemos que o presente texto é exemplar nesses dois sentidos, pois, ao oferecer um relato sobre a trajetória da gravadora Eldorado, tenta apontar também para o papel decisivo assumido por João Lara Mesquita e Aluízio Falcão - que durante boa parte da existência da empresa ocuparam respectivamente a sua presidência e direção artística - na definição do perfil que seria assumido pela empresa.

Importante lembrar aqui a nossa dificuldade em preservar a memória midiática do país. No caso específico da indústria do disco, não apenas a história das empresas e a memória de seus produtores, mas acervos fundamentais de gravadoras como Copacabana, Chantecler, Continental e Marcus Pereira, entre muitas outras, podem estar desaparecendo sem jamais terem sido lançados em CD. Por essa razão, entendemos que a pesquisa acadêmica também pode desempenhar um papel fundamental na guarda e registro da memória da produção simbólica. Não têm sido poucas as catástrofes que já atingiram inúmeros arquivos e seus acervos, como incêndios e má conservação.

O Grupo Eldorado surge a partir da fundação da emissora de AM do grupo em 1958, a Rádio Eldorado AM de São Paulo, na frequência de $700 \mathrm{KHz}$. Como nos relata João Lara Mesquita, que durante um longo período dirigiu a emissora, a Eldorado foi fundada visando predominantemente à veiculação de música erudita, que ocupava por volta de seis horas da sua programação diária. Para tanto,

[...] a Eldorado possuía modernos equipamentos e estava muito bem instalada. E além de três estúdios, tinha um grande auditório com trezentas poltronas, equipado com instrumentos como um piano Steinway $\mathcal{E}$ Sons, uma selesta Mustel, e um órgão Hammond entre outros ${ }^{1}$.

A inauguração se deu em 04/01/1958, com a transmissão ao vivo de um concerto da pianista Magdalena Tagliaferro. Além da música erudita, a rádio mantinha outros programas de cunho cultural como o Cinco minutos com Paulo Autran, em que o ator interpretava textos de diferentes autores. Vale a pena destacar o fato de esse investimento significativo no rádio, na música erudita e dirigido a um público evidentemente restrito ter ocorrido no ano de 1958, quando a presença da TV já implicava a perda tanto de quadros técnicos e artísticos quanto de receita publicitária por parte do rádio.

Assim, o investimento na constituição da emissora suscita duas questões. Em primeiro lugar, parece apontar para o fato de que a criação da emissora não respondeu apenas a interesses puramente econômicos, mas também à busca de um maior prestígio cultural e artístico por parte do Grupo Estado, especialmente se considerarmos que a emissora de FM, surgida em 1975, também manteve a música clássica em sua programação até os anos 1990. Além disso, 
demonstra que, apesar da crise, o rádio ainda possibilitava o desenvolvimento de um projeto ambicioso, dedicado a um público de maior nível cultural e econômico que seria, em princípio, alvo prioritário da televisão².

\section{O ESTÚDIO ELDORADO}

O Estúdio Eldorado surgiu em 1971 com o objetivo prioritário de atender às demandas do mercado publicitário. Eduardo Andrade ${ }^{3}$ aponta para uma tendência à terceirização da produção por parte das emissoras de rádio, que teria ocorrido aqui e nos EUA já a partir da década de 1950. Ela se devia, num primeiro momento, ao surgimento da tecnologia de gravação em fita magnética, que permitia um barateamento dos custos de gravação. Mas entendo que não podemos deixar de considerar o fato de que, pressionado pelo crescimento do mercado televisivo, o rádio perdia espaço na área de produção publicitária e, em pouco tempo, não teria mais condições de manter uma estrutura de produção para essa atividade.

Em São Paulo, o atendimento à demanda publicitária parece ter sido a razão para o surgimento de pelo menos quatro grandes estúdios entre os anos 1960 e o início da década de 1970: o RGE (Rádio Gravações Elétricas), criado ainda nos anos 1960 por José Scatena, e que se tornaria a gravadora de mesmo nome; os Estúdios Reunidos, criados pela Gazeta para atendimento a clientes externos (para produção fonográfica e publicitária); o Nosso Estúdio, criado por Walter Santos e Tereza Souza em 1974, que originaria a gravadora Som da Gente e, é claro, os Estúdios Eldorado. Vale ressaltar que, como os exemplos aqui apresentados demonstram, vivíamos então um momento de significativo crescimento da área fonográfica e os estúdios publicitários acabavam por constituir também espaços de produção musical autônoma, fora do âmbito de influência das grandes gravadoras.

O investimento na criação do Estúdio Eldorado foi bastante significativo. Ele iniciou suas atividades operando em 16 canais, tendo sido o primeiro a operar com essa tecnologia na América Latina ${ }^{4}$. Outro diferencial importante foi o de que utilizou as amplas dependências do auditório da rádio. Desse modo, além de contar com um espaço que permitia a gravação de uma orquestra sinfônica de boas proporções, o estúdio continuou contando com o piano Steinway e os demais instrumentos do antigo auditório.

O estúdio adotou um logotipo que ficaria bastante conhecido a partir de sua utilização posterior pela gravadora. Ele foi criado pelo ilustrador Edmar Salles, "que estilizou a fotografia da atriz Theda Bara com olhar de esfinge no filme Cleópatra, de 1917".

Naquele momento, muitos nomes que depois se destacariam como intérpretes e compositores no cenário fonográfico nacional já atuavam no mercado de jingles. Eduardo Andrade, por exemplo, cita entre os criadores de jingles com que trabalhou na Eldorado nomes como o do arranjador Chiquinho de Moraes, do casal Walter Santos e Tereza Souza (que seriam depois proprietários do Nosso
2. MESQUITA, João Lara. Depoimento prestado ao autor em 12 de junho de 2007.

3. ANDRADE, Eduardo Duffles. Depoimento prestado ao autor em 22 de agosto de 2007.

4. Disponível em: <http:// www. lastfm. com.br/label/ GRAVADORA+ELDORADO +-+ELDORADO+RECORDS /wiki>.

5. GIRON, Luís Antônio. $O$ discreto charme do selo Eldorado em 10 anos de carreira solo. O Estado de S. Paulo, 8 nov. 1987. 
Estúdio) e de Behring Leiros e Marconi Campos, do Trio Marayá. João Lara cita Hermeto Paschoal, Carlos Lira, Theo de Barros e Damiano Cozzela. Em relação à locação do estúdio, ele foi utilizado para a gravação de trabalhos de artistas como Caetano Veloso, Rita Lee, Tim Maia e Roberto Carlos, entre outros.

\section{A GRAVADORA ELDORADO}

A decisão acerca da criação da Gravadora Eldorado parece ter obedecido

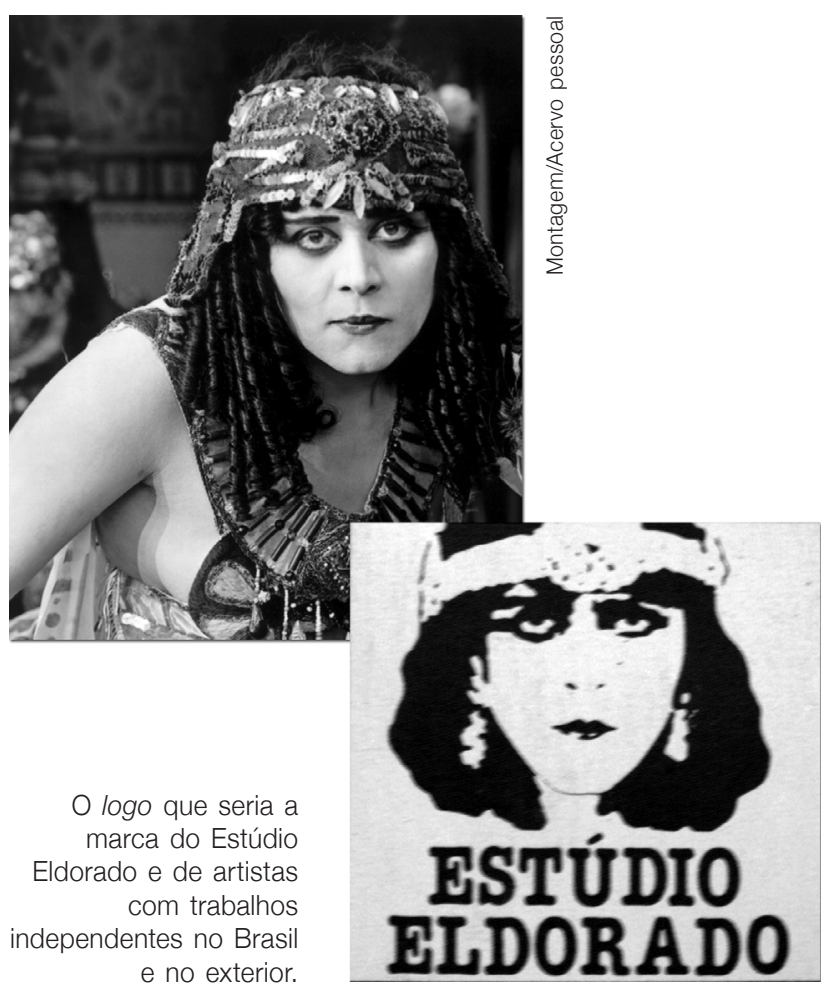
a um cálculo que envolvia tanto aspectos econômicos quanto valores artísticos e pessoais. Mas, para melhor delinear esse momento, seria preciso discutir a participação no Grupo Eldorado de João Lara Mesquita, que o dirigiria durante grande parte de sua existência.

João Lara lembra que, na segunda metade dos anos 1970, os equipamentos do estúdio tinham se tornado obsoletos e não havia, naquele momento, condições econômicas para que o Grupo Estado assumisse a sua atualização. Mas ele entendia que o estúdio ainda reunia boas condições para a produção fonográfica e sugeriu a criação da gravadora.

Eduardo Andrade nos oferece outros elementos para complementar esse cenário. Segundo ele, a questão não era exatamente de obsolescência tecnológica. Ocorria, na verdade, uma mudança de todo o mercado de produção de áudio, com diversos novos empreendimentos surgindo na cidade e rompendo o monopólio representado pelos estúdios aqui citados. Isso acabou gerando um maior tempo ocioso nos estúdios existentes que tornava necessária a diversificação de atividades, possibilitada pelo surgimento da gravadora. A gravadora iria gradativamente ocupar todo o espaço do Estúdio, que em pouco tempo deixaria de operar como empreendimento autônomo.

A gravadora foi inaugurada em 1977 com o lançamento, no ano do centenário do choro, do disco Revendo com a Flauta os Bons Tempos do Chorinho, interpretado pelo conjunto de Carlos Poyares. Mas, antes de discutir a trajetória da empresa, gostaria de relacionar seu surgimento ao contexto da indústria no período. Afinal, o ano de fundação da Gravadora Eldorado, 1977, é também o ano de lançamento do disco Feito em Casa, de Antonio Adolfo, que marca o início da 
articulação de uma cena independente nacional. Rapidamente, surgem no eixo São Paulo-Rio nomes como Francisco Mário, Boca Livre, Rumo, Céu da Boca, Oswaldo Montenegro, Luli \& Lucina, o Teatro Lira Paulistana - inaugurado em São Paulo em 1979, e que dará projeção aos trabalhos de artistas como Arrigo Barnabé, Itamar Assumpção, Premeditando o Breque e Língua de Trapo, entre outros -, além da Gravadora Som da Gente, surgida em 1981.

Parece evidente que o desenvolvimento de todas essas iniciativas e carreiras denota a existência de uma demanda não plenamente atendida pelas grandes gravadoras por uma produção musical menos massificada, de maior valor intelectual e artístico. No sentido do direcionamento de sua produção, o projeto da Eldorado tinha uma identidade evidente com os dos demais artistas e empreendimentos aqui citados. Porém, seria possível classificar a gravadora

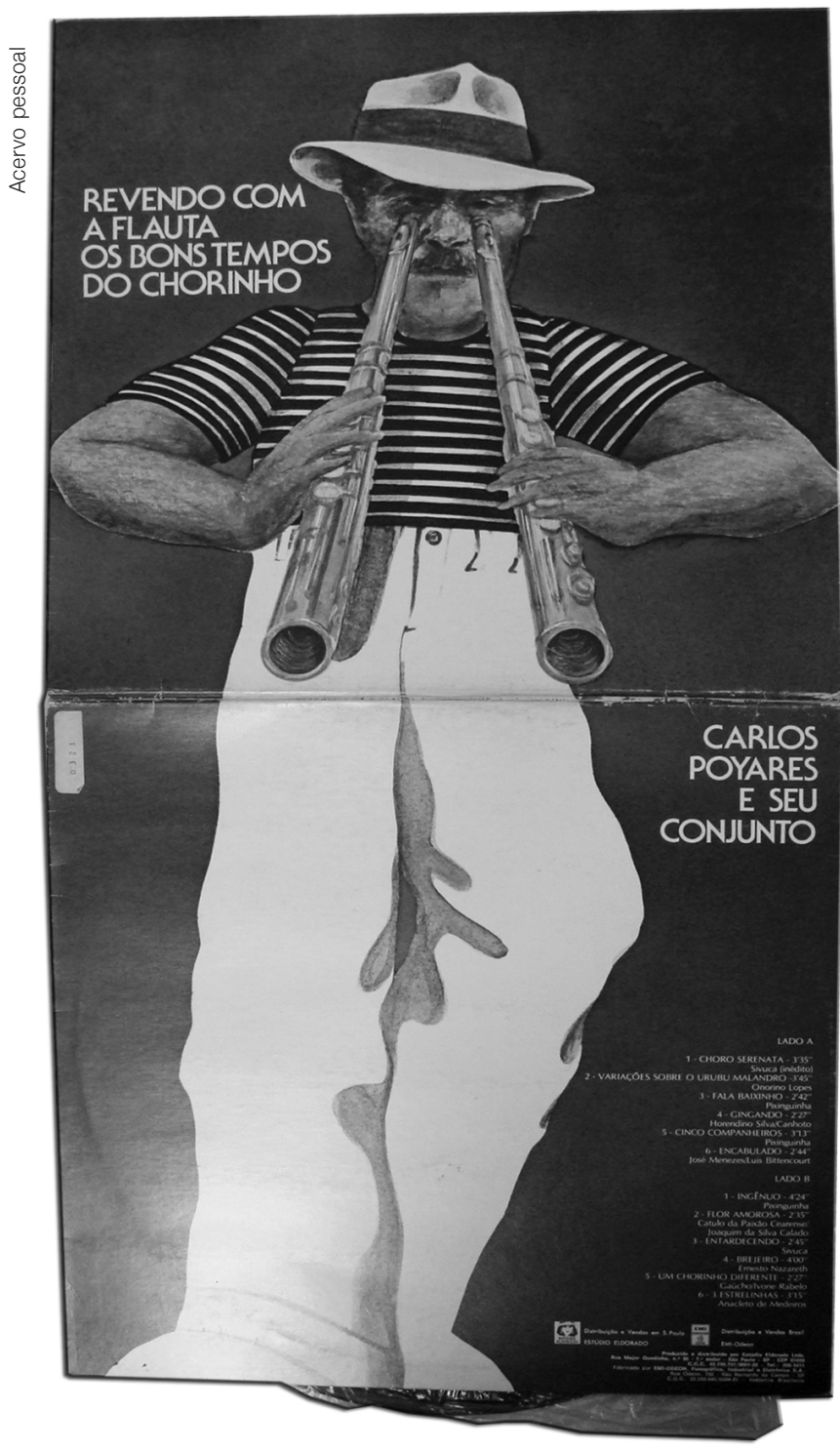

A inauguração em 1977 teve o lançamento do disco Revendo com a Flauta os Bons Tempos do Chorinho, interpretado pelo conjunto de Carlos Poyares. de independente? Essa não nos parece uma questão simples. Se considerarmos a constituição do Grupo Estado enquanto um conglomerado de comunicação de atuação múltipla, a Eldorado evidentemente não poderia ser pensada como uma gravadora independente nos moldes tradicionais de uma empresa única, de atuação local e vinculada a um mercado segmentado. Por outro lado, embora tenha atuado em um leque diversificado de segmentos e contado efetivamente com os jornais e emissoras do grupo para a divulgação de suas produções, ela nunca optou decididamente pelo massivo, dedicando a melhor parte de sua produção a trabalhos de evidente valor histórico e documental e que não tinham, certamente, maiores pretensões de sucesso comercial. De qualquer forma, Aluizio Falcão, então coordenador artístico 
comunicação \& educação • Ano XVI • número 1 • jan/jun 2011

do selo, afirmava em 1979 que a Eldorado apostava num público "carente de discos de alta qualidade, que passa horas nas lojas de discos atrás de algo diferenciado e criativo" ${ }^{\prime}$. Ele também refutava a relação entre a gravadora e o mercado independente, fugindo de qualquer rotulação da empresa dentro de um quadro de embate ideológico entre independentes e grandes gravadoras, que envolvia desde questões como a liberdade artística, a internacionalização do consumo e a concentração do poder econômico, até o tema da alienação e o papel do intelectual na sociedade.

O vínculo com a música brasileira e com a produção de trabalhos de interesse histórico seria mantido durante grande parte da existência da gravadora, principalmente pela atuação do próprio Aluízio, que fora diretor artístico da Gravadora Marcus Pereira. Compositor e publicitário, ele chegara à Rádio Eldorado por iniciativa de Carlos Vergueiro e acabou se unindo ao projeto da gravadora e respondendo por muitos de seus projetos. Isso ocorreria especialmente entre 1979 e 1982, período em que João Lara Mesquita esteve nos EUA estudando música.

Dos trabalhos produzidos pela Eldorado e que representaram o resgate de tradições de nossa história musical, podem ser citados $O$ Canto dos Escravos (1982), que reúne canções de trabalho interpretadas por Geraldo Filme, Clementina de Jesus e Tia Doca; Brincadeiras de Roda, Histórias e Canções de Ninar, produzido por Antonio Nóbrega, que reunia cantigas tradicionais infantis; além de trabalhos de Nelson Sargento e Elton Medeiros. Também foram produzidos discos com depoimentos (como um histórico, feito por Cartola) e mesmo poesias (as gravações do programa Cinco Minutos com Paulo Autran).

SOUZA Cláudia de. Nem pequena, nem grande: diferente. O Estado de S. Paulo, 15 set. 1979

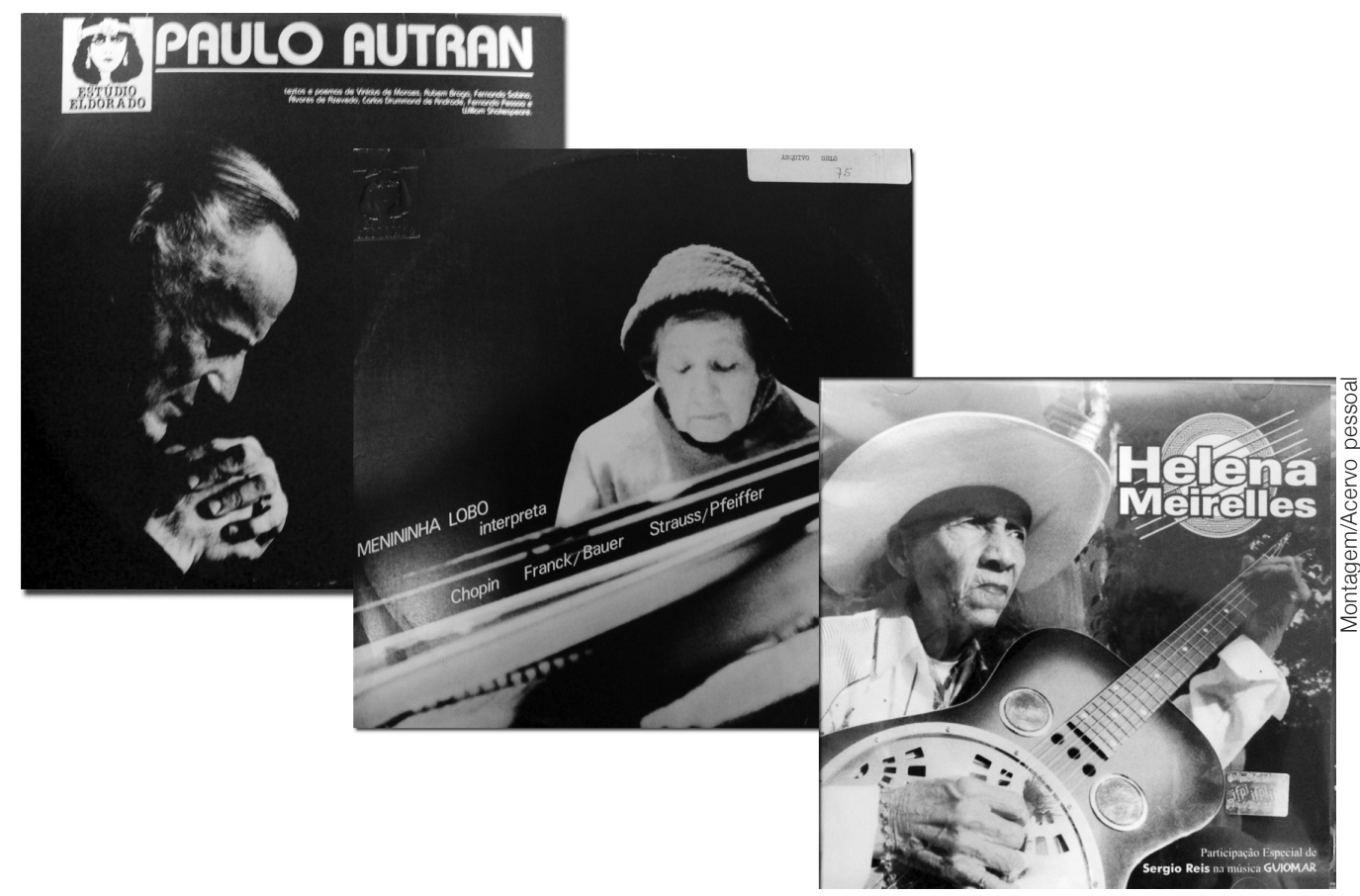

Ecletismo, resgates históricos e oportunidade para novos talentos. Autran, Menininha Lobo e Helena Meirelles, pela Eldorado. 
Na área da música erudita, a gravadora foi, durante os anos 1980, uma das mais importantes do país, principalmente após João Lara retornar dos EUA em 1982. A gravadora inclusive produziu - em função de suas instalações - o primeiro disco de uma orquestra sinfônica gravado em estúdio no Brasil (Uma Sonata para Cordas, de Carlos Gomes, gravada pela Orquestra Sinfônica de Campinas sob a regência do maestro Benito Juarez). E além de registrar trabalhos de intérpretes como Menininha Lobo e Antonio Menezes, e as gravações de programas da emissora AM, como Piano ao Cair da Tarde, a gravadora era responsável pela produção dos discos dos vencedores do Prêmio Eldorado de Música Erudita, concebido em 1985 por José Luis Paes Nunes a pedido de João Lara. O prêmio, segundo depoimento deste último, resgatava a ideia de um concurso de piano criado ainda nos anos 1960 por Carlos Vergueiro e que teve João Carlos Martins como um de seus vencedores. O Prêmio Eldorado teve 11 edições, revelando "nomes da música erudita como o quarteto de clarinetes Sujeito a Guincho e o trompista Roberto Minczuk, vencedor da primeira edição do prêmio"?.

Mas a gravadora teve uma atuação bastante eclética, gravando nomes como Thaide e DJ Hum (rap), Raíces de America (música latino-americana), Sepultura (rock), Ratos de Porão (hardcore) e Daniela Mercury (Axé Music), entre muitos outros.

\section{A CRISE DA GRAVADORA}

A gravadora, como todo o mercado fonográfico nacional, sofreu fortemente com a crise econômica que marcou grande parte da década de 1980 e, especialmente, com o Plano Collor no início dos anos 1990. Além desses fatores, João Lara cita como grande problema para a empresa a forma pela qual as grandes gravadoras internacionais (majors) passaram a controlar o mercado, estabelecendo práticas como a venda em consignação ou a prazos dilatados, que não podiam ser acompanhadas por gravadoras menores num ambiente inflacionário como o dos anos 1980.

Além disso, a Eldorado dependia, para seu sucesso, de um aspecto fundamental no ecossistema de produção e distribuição de discos, representado pela loja especializada. A fragilização desse setor, assolado pela pirataria e, especialmente, pela estratégia de atuação das grandes gravadoras, que privilegiaram a venda maciça em grandes superfícies (supermercados e magazines), acabou por eliminar um espaço onde vendedores especializados podiam apresentar novos e diferenciados produtos a seus clientes. A primeira decisão da Eldorado, no final dos anos 1980, foi

[...] deixar passar o furacão e tentar de novo fazer um disco por ano pra gente [...]. Então enxugamos o que foi possível e voltamos àquela história: quando aparecesse um grande artista que a gente julgasse que merecesse um disco, que nunca fez um disco, que a gente veja que o aparato pra ele poder fazer o disco é barato, suficiente, a gente vai e faz. Senão, esquece. E ainda assim a gente conseguiu fazer algumas coisas muito boas, como, por exemplo, a Helena Meirelles ${ }^{8}$.
7. SERGL, M. J., VICENTE, E. O mercado fonográfico nacional e a produção de música erudita. Trabalho apresentado no VII Encontro dos Núcleos de Pesquisa em Comunicação - NP Mídia Sonora. Santos: Intercom, 2007.

8. Conforme depoimento cedido ao autor, op. cit. 
Posteriormente, em 1997, a Eldorado envolveu-se num projeto de distribuição de discos, motivada pela constatação de que eram limitadas as perspectivas para seu crescimento enquanto gravadora. Atuando como distribuidora, e praticamente encerrando suas atividades enquanto gravadora, a Eldorado chegou a representar aproximadamente 40 selos $^{9}$. Além de se propor a atender a todas as lojas especializadas, o projeto de distribuição da Eldorado buscava também reduzir os custos de produção dos selos, garantindo um aumento do seu poder de negociação junto aos fornecedores.

Em 2001, no entanto, o projeto acabou por fracassar, e as condições de sobrevivência da própria empresa, mesmo na sua volta às atividades como gravadora, tornaram-se incertas.

O próprio Prêmio Eldorado de música enfrentou grandes dificuldades a partir da segunda metade dos anos 1990:

O prêmio durou 11 anos. Durante 11 anos conseguiu ser autossustentável, encontrar parceiros na indústria de anunciantes que nos suportassem. Até que chegou uma época que parou de vender. Nós não decidimos acabar com o prêmio: eu fiquei 3 anos tentando vender e não consegui. Quem sabe daqui a alguns anos ele possa voltar a despertar interesse, e ele voltará ${ }^{10}$.

Diante desse quadro, João Lara decidiu pela adaptação do Prêmio para a Música Popular, transformando-o no Prêmio Visa que, surgido em 1998, contempla artistas em três modalidades (instrumentistas, vocalistas e compositores).

Mas o sucesso do prêmio não alavancou as atividades da gravadora, que passou a se dedicar quase que exclusivamente a relançamentos e à gravação do disco do vencedor do Visa.

Em 2003, ocorreu ainda a saída de João Lara Mesquita da Eldorado. Ela deveu-se, segundo João Lara, a uma decisão dos acionistas que afastou dos cargos de direção do Grupo Estado todos os membros da Família Mesquita.

\section{CONCLUSÕES}

Embora a racionalidade produtiva do capitalismo tenda a homogeneizar as ações, é preciso considerar também a liberdade de atuação de profissionais que ocupam cargos de direção das empresas como capazes de imprimir rumos um tanto diferenciados para seus empreendimentos. Entendo que seja esse o caso do Grupo Eldorado. No âmbito da produção musical, a experiência da gravadora do grupo mostra como a formação pessoal de seu diretor foi decisiva num empreendimento que teve papel destacado para a produção musical do país, tanto no campo popular quanto no erudito, durante ao menos duas décadas. Além disso, demonstra que é preciso revalorizar o papel das pequenas

9. DISTRIBUIDORA Eldorado abre mercado para independentes. O Estado de S. Paulo, 2 abr. 1997.

10. João Lara Mesquita em depoimento ao autor, op. cit. gravadoras nacionais no contexto da renovação da música brasileira, entendendo que foi a partir das iniciativas dessas empresas que um significativo número de artistas pôde transformar suas criações em produtos fonográficos.

Já no âmbito da produção radiofônica, a criatividade da empresa - cuja produção carece ainda de uma análise mais detalhada - pode nos ajudar a 
repensar as possibilidades de produção e utilização do rádio mesmo em contextos tão tradicionais quanto o do jornalismo e da veiculação musical. Além disso, entendo que a experiência da Rádio Eldorado acaba por evidenciar também o caráter fortemente regionalizado da produção radiofônica, condição que deve ser levada em conta para a formulação de uma história do veículo menos reducionista, capaz de dar conta de um cenário mais complexo e fragmentado do que o sugerido pelo senso comum.

\section{REFERÊNCIAS BIBLIOGRÁFICAS}

DISTRIBUIDORA Eldorado abre mercado para independentes. O Estado de S. Paulo, 2 abr. 1997.

GIRON, Luís Antônio. O discreto charme do selo Eldorado em 10 anos de carreira solo. O Estado de S. Paulo, 8 nov. 1987.

GUERRINI JR., Irineu. Rádio de elite: o papel da Rádio Gazeta no cenário sociocultural de São Paulo nos anos quarenta e cinquenta. Projeto de Pesquisa Docente não publicado. São Paulo, Faculdade de Comunicação Cásper Líbero/ Centro Interdisciplinar de Pesquisa, 2005.

SERGL, M. J., VICENTE, E. O mercado fonográfico nacional e a produção de música erudita. Trabalho apresentado no VII Encontro dos Núcleos de Pesquisa em Comunicação - NP Mídia Sonora. Santos: Intercom, 2007.

SOUZA, Cláudia de. Nem pequena, nem grande: diferente. O Estado de S. Paulo, 15 set. 1979.

\section{Depoimentos}

ANDRADE, Eduardo Duffles. Depoimento prestado ao autor em 22 ago. 2007.

MESQUITA, João Lara. Depoimento prestado ao autor em 22 ago. 2007. 

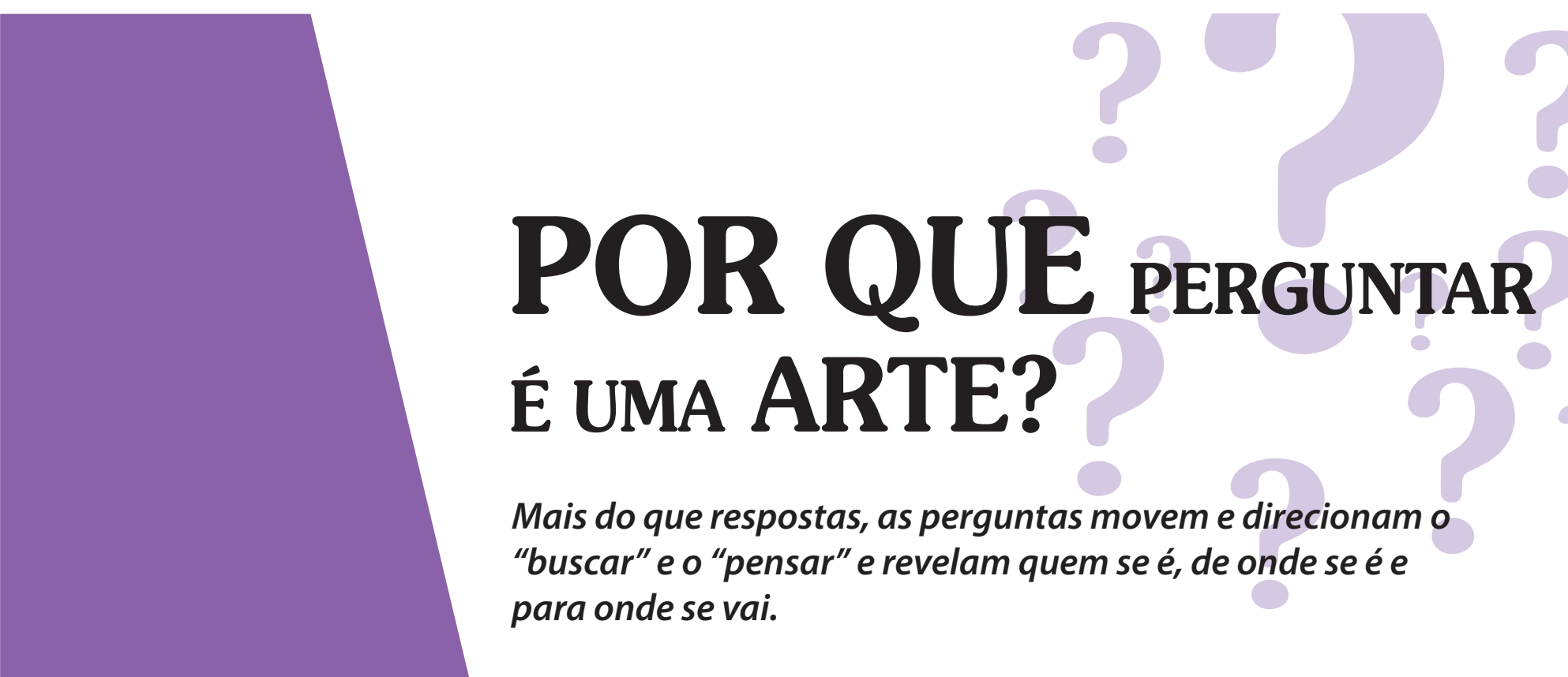

Mais do que respostas, as perguntas movem e direcionam o "buscar" e o "pensar" e revelam quem se é, de onde se é e para onde se vai.

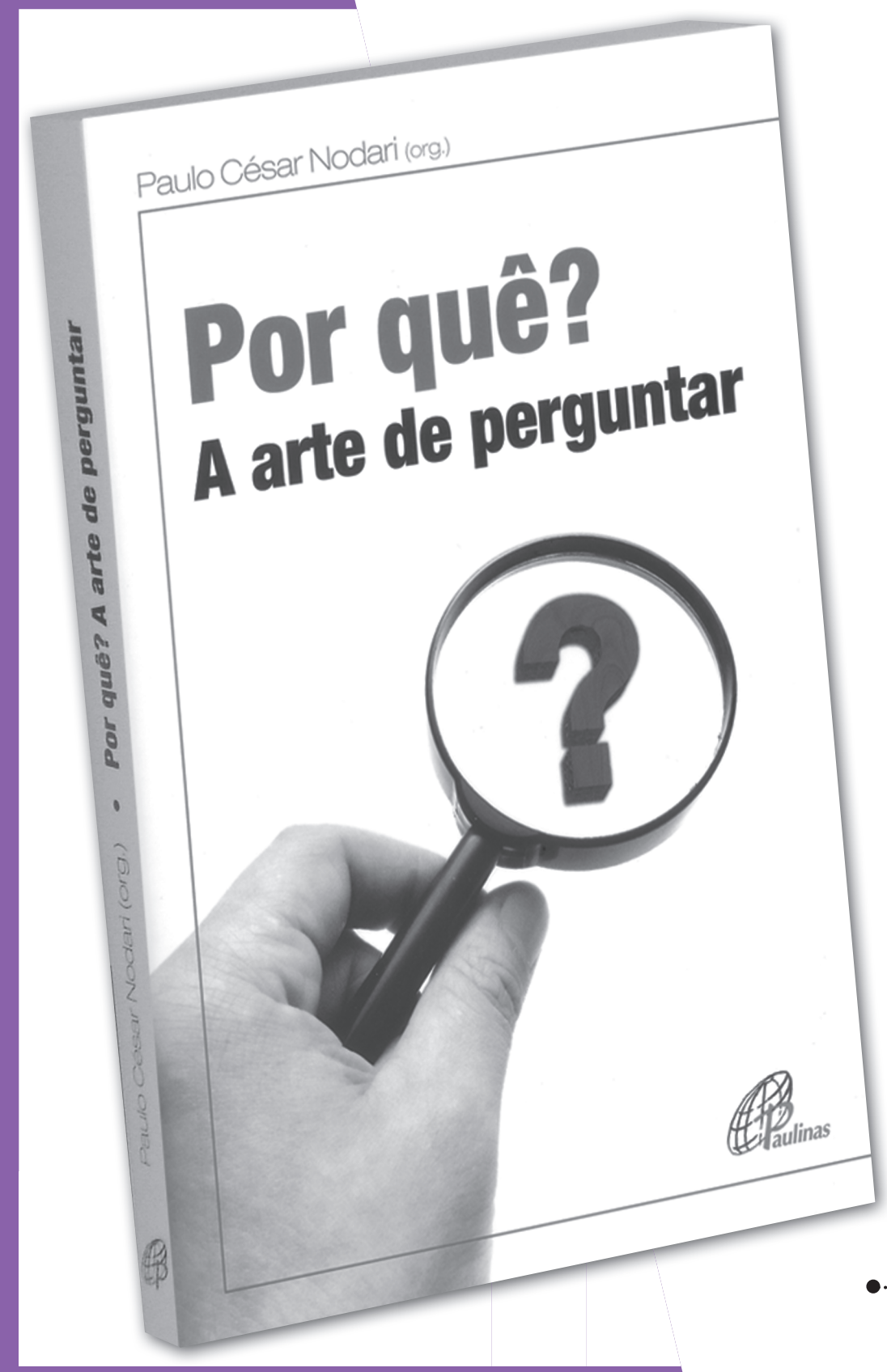

Dor que as coisas são assim e não de
outro modo? Por que nos admiramos? Por que sermos virtuosos, justos e éticos? Por que isso e não aquilo? Perguntar faz parte da vida. É sinal de inteligência e de humildade dar-se conta de que não se sabe tudo. Mas o que significa perguntar? Artigos reunidos nesta obra trazem considerações sobre o tema e algumas perguntas que, cedo ou tarde, acabamos por fazer à realidade e a nós mesmos.

Dentre as muitas possíveis, os autores selecionaram quinze - das clássicas do pensamento filosófico e pedagógico até interrogações sobre o sentido último da existência humana. Em comum, essas perguntas são bons exemplos da urgência do movimento dialético entre 0 saber e o não saber. E os especialistas ensaiam algumas respostas, dispostos a provocar a curiosidade e, quem sabe, despertar para novos e fascinantes questionamentos. 